\title{
LIPOMA OF THE CORPUS CALLOSUM
}

\author{
BY
}

\author{
W. H. P. CANT and R. ASTLEY \\ From the Children's Hospital, Birmingham
}

(RECEIVED FOR PUBLICATION FEBRUARY 18, 1952)

A lipoma of the corpus callosum is one of the few intracranial tumours that may present a pathognomonic appearance on direct radiography. Nevertheless, as it is a relatively rare lesion, the diagnostic features are not widely known; this perhaps justifies the following report of a single but typical example of this abnormality.

From the literature, List, Holt and Everett (1946) collected 100 examples of lipoma of the brain, of which 30 involved the corpus callosum. Most of these were incidental findings at necropsy. The tumour had no characteristic clinical picture and diagnosis was only possible radiologically. Sutton (1949) was able to find mention of the radiological findings in only nine cases including his own.

\section{Case Report}

E.A. was born in June, 1946. At birth a swelling in the frontal region was noticed and was said to increase in size during the first few months of life. This 'tumour' was seen at The Children's Hospital, Birmingham, in September, 1946. It was about the size of a crown and was situated in the midline of the scalp, one centimetre in front of the anterior fontanelle. Surgical removal showed it to be a lipoma. A radiograph of the skull at the time did not seem to show any unusual features.

In September, 1951, at the age of 5 years, the boy had a generalized convulsion. Nothing unusual was found on clinical examination and no family history of epilepsy was obtained. A routine radiograph of the skull showed a picture which was at once recognized in the $\mathrm{X}$-ray Department as being typical of lipoma of the corpus callosum.

Radiographs. The lateral film revealed an area of mottled calcification measuring about $2 \frac{1}{2} \times 3 \frac{1}{2} \mathrm{~cm}$. situated $4 \mathrm{~cm}$. above the floor of the anterior fossa in the line of the coronal suture (Fig. 1). The skull here had slightly increased translucency, largely obscured by the calcification.

The postero-anterior film showed two curved plaques of calcification, one on each side of the midline. They partly enclosed an area the shape of an inverted pear measuring $4 \times 4 \mathrm{~cm}$. (Fig. 2).

Encephalograms. The lateral ventricles were slightly dilated but not deformed; they were symmetrically displaced laterally, so that their medial walls lay adjacent

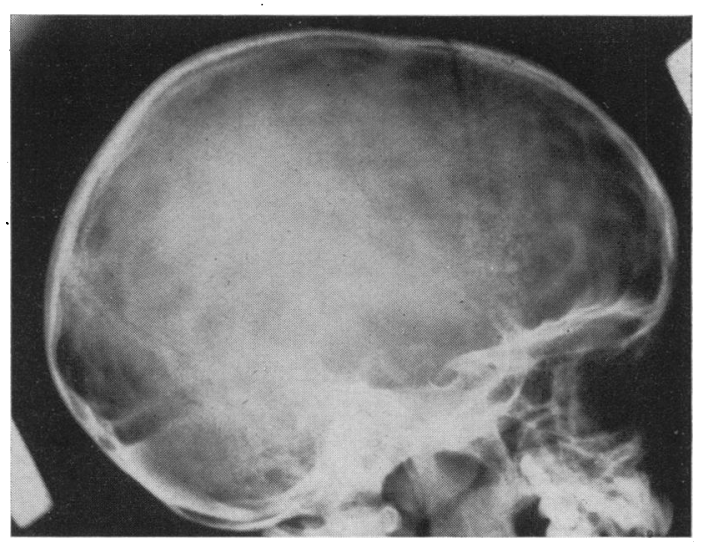

Fig. 1.-Lateral film showing an area of mottled calcification near the coronal suture.

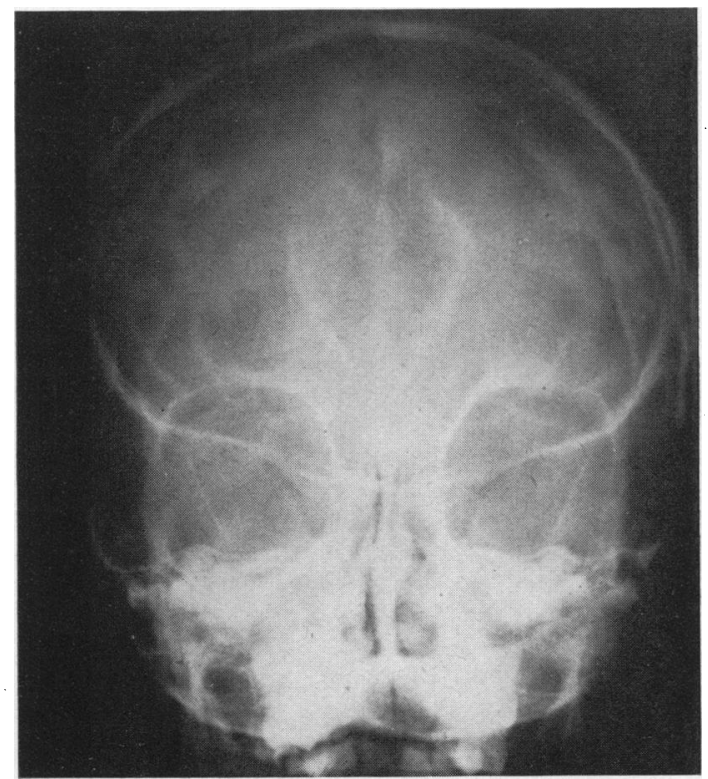

Fig. 2.-Postero-anterior film showing two plaques of calcification, one on each side of the midline. 
to the calcified plaques. The posterior part of the third ventricle was elevated (Figs. 3 and 4).

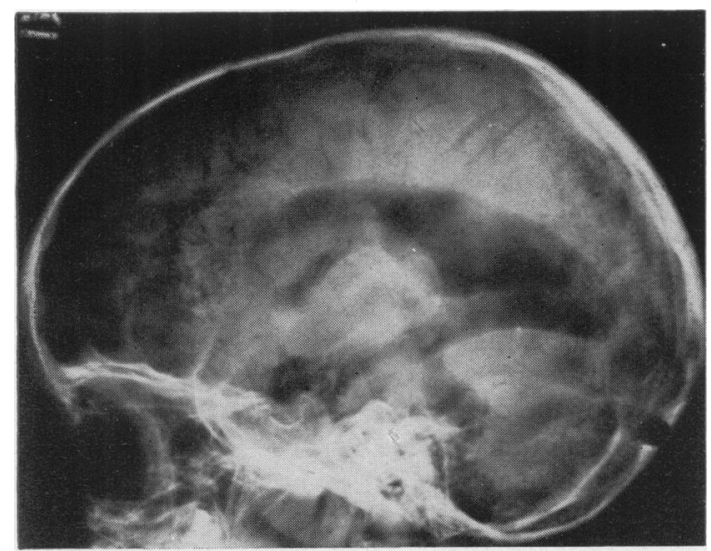

Fig. 3.

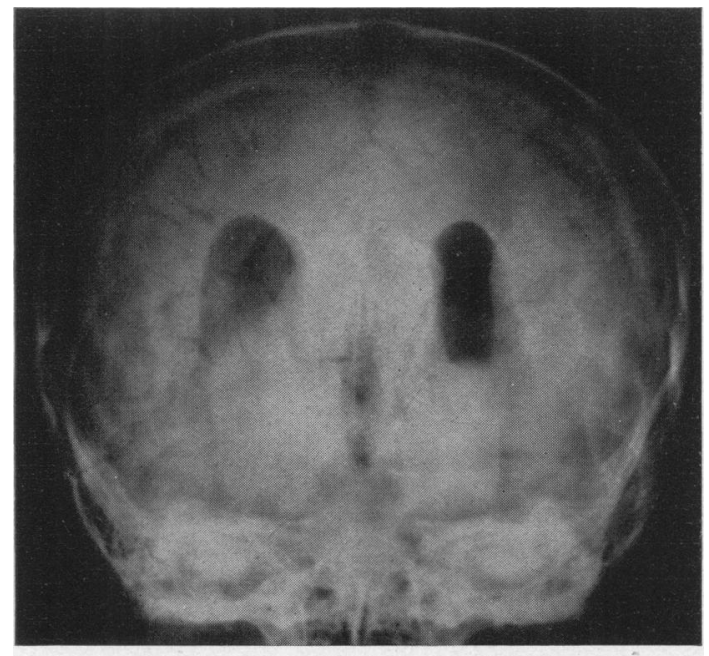

FIG. 4.

FIGs. 3 AND 4.-Films showing lateral displacement of the ventricles.

The radiographs taken when the patient was 4 months old were reviewed. In the posterior frontal region the lateral view showed a slight but definite area of translucency, containing a few faint flecks of calcification. Because of the very unsatisfactory results in the only four recorded cases so far subjected to operation no further treatment is at present contemplated.

\section{Discussion}

The radiological findings exactly parallel those described by Sosman (Dyke, 1939; Sosman, 1946) and by other authors (List et al., 1946; Amyot, 1946; Ehni and Adson, 1945; Sutton, 1949). The characteristic features are (1) the curved plaques of calcification, symmetrically arranged on each side of the midline in the region of the corpus callosum; (2) the translucency of the fat (although this may be obscured by the calcification of the capsule); (3) the displacement of the lateral ventricles on each side of the midline mass demarcated by the calcification.

Most frequently the lipoma lies anteriorly in the corpus callosum, which it partly replaces. The posterior part of the corpus may be absent. The lesion is considered to be a perversion of differentiation of the primitive meninges, i.e. it is a malformation rather than a true tumour. This theory is favoured by the midline situation of the 'tumour? and its occasional discovery in early childhood, for example in the patient of List et al. (1946) aged 3 days. In the present case, which showed calcification at 4 months old, there was the association with a further congenital lipoma on the scalp. Although there is no other mention of such a double midline lesion, Arnold (List et al., 1946) described an extracranial lipoma of the frontal region that extended through the anterior fontanelle and metopic suture between the frontal lobes.

The anterior cerebral arteries are often incorporated in a lipoma of the corpus callosum; this anatomical relationship has lead to permanent postoperative disorders of cerebral function or death in the four cases recorded where surgery has been attempted.

Because the clinical picture is not characteristic and because of the risk of attempted surgical removal a correct appreciation of the radiological features is of the highest importance.

\section{Summary}

A case is described that showed the radiological appearances of a lipoma of the corpus callosum. The lesion is a congenital malformation, with replacement of the corpus by fatty tissue, rather than a true tumour. It presents no clear-cut clinical picture, but the pathognomonic $x$-ray appearances may make diagnosis possible during life. This is important because surgical removal appears to be contraindicated.

\section{REFERENCES}

Amyot, R. (1946). Un. méd. Can., 75, 1391.

Dyke, C. G. (1939). In Diagnostic Roentgenology, Ed. R. Golden. New York.

Ehni, G. J. and Adson, A. W. (1945). Arch. Neurol. Psychiat., Chicago, 53, 299.

List, C. F., Holt, J. F. and Everett, M. (1946). Amer. J. Roentgenol. $55,125$.

Sosman, M.C. (1946). Radiology, 46, 119 (in discussion on a paper by Echternacht, A. P. and Campbell, J. A.)

Sutton, D. (1949). Brit. J. Radiol., 22, 534. 